\title{
The importance of reporting housing and husbandry in rat research
}

\section{Eric M. Prager ${ }^{*}$, Hadley C. Bergstrom ${ }^{2}$, Neil E. Grunberg ${ }^{1,3,4}$ and Luke R. Johnson ${ }^{1,2,3,5}$}

\author{
1 Program in Neuroscience, Uniformed Services University, Bethesda, MD, USA \\ 2 Department of Psychiatry, Uniformed Services University, Bethesda, MD, USA \\ ${ }^{3}$ Center for Neuroscience and Regenerative Medicine, Uniformed Services University, Bethesda, MD, USA \\ ${ }^{4}$ Department of Medical and Clinical Psychology, Uniformed Services University, Bethesda, MD, USA \\ ${ }^{5}$ Center for the Study of Traumatic Stress, Uniformed Services University, Bethesda, MD, USA \\ *Correspondence: eric.prager@usuhs.mil
}

In 1963, the National Institutes of Health (NIH) first issued guidelines for animal housing and husbandry. The most recent 2010 revision emphasizes animal care "in ways judged to be scientifically, technically, and humanely appropriate" (National Institutes of Health, 2010, p. XIII). The goal of these guidelines is to ensure humanitarian treatment of animals and to optimize the quality of research. Although these animal care guidelines cover a substantial amount of information regarding animal housing and husbandry, researchers generally do not report all these variables (see Table 1). The importance of housing and husbandry conditions with respect to standardization across different research laboratories has been debated previously (Crabbe et al., 1999; Van Der Staay and Steckler, 2002; Wahlsten et al., 2003; Wolfer et al., 2004; Van Der Staay, 2006; Richter et al., 2010, 2011). This paper focuses on several animal husbandry and housing issues that are particularly relevant to stress responses in rats, including transportation, handling, cage changing, housing conditions, light levels and the light-dark cycle. We argue that these key animal housing and husbandry variables should be reported in greater detail in an effort to raise awareness about extraneous experimental variables, especially those that have the potential to interact with the stress response.

Rats used in scientific research are usually transported from a breeder to an institution's animal housing facility prior to experimentation. NIH guidelines on animal care do not provide standards on the duration of time to allow for acclimation to the new colony prior to experimentation, even though transportation can be stressful (Van Ruiven et al., 1998; Capdevila et al., 2007). Transporting rats [male Sprague-Dawley (SD), 175-200 g] for $5 \mathrm{~h}$ to a new facility has been found to decrease body weight, decrease overall activity levels, and increase heart rate (HR) for up to four days after transportation (Capdevila et al., 2007). Blood corticosterone (CORT), a physiological indicator of the stress response, has also been reported to be significantly lower in male and female Wistar rats 1 day after a prolonged (15 h) transport compared to control animals, but returns to pre-transport values 3 days after arrival in a new environment (Van Ruiven et al., 1998). Therefore, in agreement with Van Ruiven and colleagues, 3-4 days should be a sufficient period for acclimation after which rats' stress parameters return to pretransport levels.

Although not a component of $\mathrm{NIH}$ guidelines for housing and husbandry, most researchers "gentle" or "handle" rats prior to experimentation with the intention of habituating them to human contact, thereby decreasing stress responses. However, evidence to the contrary indicates that handling induces a rapid and significant elevation of physiological stress responses in rats that may persist for 30-60 min or longer (Black et al., 1964; Sharp et al., 2002a,b, 2003; Balcombe et al., 2004). Handling male SD rats for 20 consecutive days significantly increases mean $\mathrm{HR}$, blood pressure, and serum CORT concentrations (Armario et al., 1986a,b; Balcombe et al., 2004). The persisting CORT response after the initial handling may affect performance in subsequent behavioral tests (Brown and Martin, 1974). Interestingly, rats show minimal habituation to these physiological markers of stress (Balcombe et al., 2004). Therefore, daily handling may not reduce stress as commonly thought, but instead, may actually work to increase the stress response. Although it is difficult to estimate a precise timeframe for testing after daily handling, the data cited above, as well as other experimental data (see
Sapolsky et al., 1984; Flores et al., 1990) suggest that at least 30-60 min should elapse before conducting stress-sensitive procedures. Given this caveat, we recommended that authors report latency from handling to procedure and consider all handling in their experimental design.

National Institutes of Health guidelines indicate that cages should be changed as often as necessary to ensure that animals are clean and dry, but that cleaning frequency is a matter of the judgment of animal care personnel (National Institutes of Health, 2010, p. 75). Empirical evidence suggests that excessive cage changes may be stressful to rats (Kacergis et al., 1996; Thulin et al., 2002; Balcombe et al., 2004; Burn et al., 2006). Cage cleaning has been linked with increases in cardiovascular parameters and general activity in male SD and Wistar rats (Saibaba et al., 1996; Schnecko et al., 1998; Doerning, 1999; Duke et al., 2001; Burn et al., 2006). Burn et al. (2006) examined the effects of cage cleaning (twice weekly, weekly, or biweekly) across two commonly used rat strains (Wistar and SD). Rats with cage cleanings biweekly displayed fewer defensive behaviors (i.e., biting and audible vocalizations) and struggled less during handling than did rats with cages cleaned weekly or twice weekly. In contrast, it took longer for anxiety-like behaviors to return to pre-stress levels in rats that had cages cleaned less often. Because cage changing may affect behavioral and biological stress responses, it is important for investigators to include this information in experimental reports and to be consistent in frequency of cage changing among treatment groups. Investigators should consider biweekly cage cleaning, if possible, or no more than weekly, if necessary.

Numbers of animals per cage, size of cages, and presence or absence of physical enrichment affect stress responses 


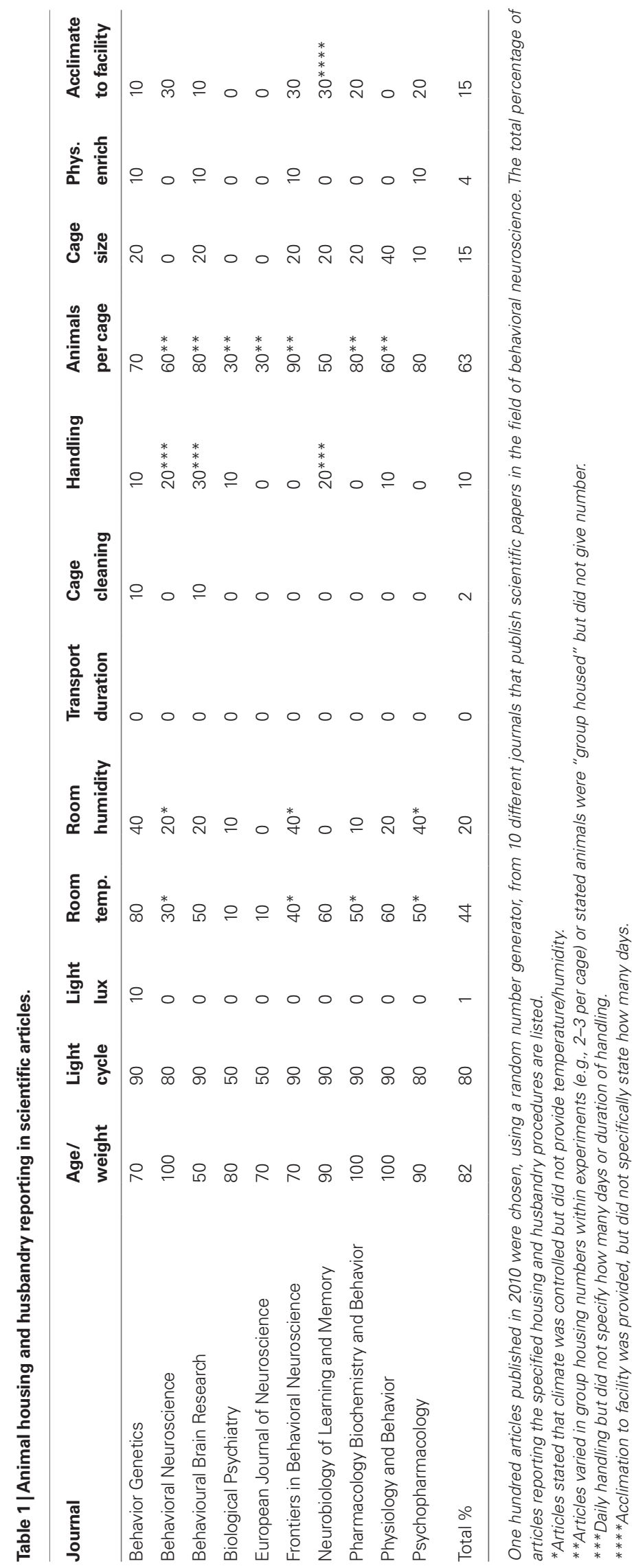


and a variety of behaviors. This point was reported in the classic work of psychologists Mark Rosenzweig, Marian Diamond, and colleagues who pioneered studies of behavioral and biological effects of enriched environments (Rosenzweig et al., 1962, 1967; Diamond et al., 1972, 1976; Bennett et al., 1974). Socially housing rats ("social enrichment") decreases fearfulness, improves cognitive activities (Hatch et al., 1963; Johnson et al., 1972; Morgan and Einon, 1975; Patterson-Kane et al., 2004), increases locomotor activities (Elliott and Grunberg, 2005; Kim et al., 2007), and shortens recovery after intrusive surgeries (Gornicka-Pawlak et al., 2009). However, space and sex also must be considered. For instance, whereas cage crowding was associated with higher plasma CORT in males, crowded females showed lower CORT (Elliott and Grunberg, 2005). Crowding may induce fighting (especially among males) which may result in increased physiological reactivity. If enough space is available to balance the needs of the rat including sanitation, physical contact, and motor activity, then rats should be housed in groups of two or more (Patterson-Kane et al., 2004), unless the experiment requires individual housing. Group housing in appropriately spaced cages allows for increased socialization and results in a significant decrease in mean arterial blood pressure and HR compared with isolated male and female SD rats (Sharp et al., 2002a,b, 2003). At times, experimental protocols require social isolation. Isolating rats may potentiate the effects of stress as some rats (e.g., male Wistar rats) have been shown to exhibit increased behavioral abnormalities including hyperactivity (Gornicka-Pawlak et al., 2009) and increased substance $\mathrm{P}$ levels in the dorsal periaqueductal gray, a midbrain region involved in aversion behavior, pain regulation and the fear response (Brodin et al., 1994). If isolation is necessary, then the use of a cage divider may be employed, which allows for social interactions and enhanced social enrichment without compromising isolation needs (Boggiano et al., 2008).Toys in cages (or "physical enrichment") also can affect behavioral performance in rats (e.g., Elliott and Grunberg, 2005) and should also be considered and reported. It is important to note here that single housing has not consistently been shown to increase stress response, especially in mice (Reber and Neumann, 2008; Singewald et al., 2009).
Light luminance in housing facilities is another variable that has a marked influence on the physiology, circadian rhythm, and behavior of rats (Tucker et al., 1984; Azar et al., 2008). Compared with SD rats housed in a standard 12:12 light-dark cycle with normal illumination (200 lux), the HR of undisturbed male (but not female) rats was decreased under dim lights (10 lux) during a 12:12 photocycle. Increasing the dark cycle to $16 \mathrm{~h}$ (8:16 photocycle) under normal light conditions (200 lux) decreased the HR of undisturbed males. Changing the light cycle to be more species specific (e.g., dim light or longer dark period in rats) reduced HR during periods of day and night when rats were left undisturbed (Tucker et al., 1984; Azar et al., 2008). However, neither dim light nor long nights affected HR responses during experimentation (Azar et al., 2008). Behavioral research is commonly carried out during the light phase, an approach that is ethologically incorrect in nocturnal animals. Reverse light cycle allows for measurements during rats' active period, whereas direct light cycles result in measurements during rats' inactive period. Although existing data on the impact of testing phase on the stress response is limited, investigators should consider and report illumination levels, light cycles, and lighting conditions when taking behavioral and biological measurements.

The data reviewed here suggests that rat transport, handling, cage changing, housing conditions, light levels, and the light-dark cycle all have the potential to interact with the stress response. However, these interactions may not always be easily transferred to other rodent models. Therefore we recommend documenting in detail all housing and husbandry procedures as part of standard experimental reporting, so that informed comparisons of experimental results can be made across different laboratories.

\section{REFERENCES}

Armario,A., Lopez-Calderon, A., Jolin, T., and Castellanos, J.M. (1986a).Sensitivity of anterior pituitary hormones to graded levels of psychological stress. Life Sci. 39, $471-475$.

Armario, A., Montero, J. L., and Balasch, J. (1986b). Sensitivity of corticosterone and some metabolic variables to graded levels of low intensity stresses in adult male rats. Physiol. Behav. 37, 559-561.

Azar, T. A., Sharp, J. L., and Lawson, D. M. (2008). Effect of housing rats in dim light or long nights on heart rate. J. Am. Assoc. Lab. Anim. Sci. 47, 25-34.
Balcombe, J. P., Barnard, N. D., and Sandusky, C. (2004). Laboratory routines cause animal stress. Contemp. Top. Lab. Anim. Sci. 43, 42-51.

Bennett, E. L., Rosenzweig, M. R., Diamond, M. C., Morimoto, H., and Hebert, M. (1974). Effects of successive environments on brain measures. Physiol. Behav. 12, 621-631.

Black, R. W., Fowler, R. L., and Kimbrell, G. (1964). Adaptation and habituation of heart rate to handling in the rat. J. Comp. Physiol. Psychol. 57, 422-425.

Boggiano, M. M., Cavigelli, S. A., Dorsey, J. R., Kelley, C. E., Ragan, C. M., and Chandler-Laney, P. C. (2008). Effect of a cage divider permitting social stimuli on stress and food intake in rats. Physiol. Behav. 95, 222-228.

Brodin, E., Rosen, A., Schott, E., and Brodin, K. (1994). Effects of sequential removal of rats from a group cage, and of individual housing of rats, on substance $\mathrm{P}$, cholecystokinin and somatostatin levels in the periaqueductal grey and limbic regions. Neuropeptides 26, 253-260.

Brown, G. M., and Martin, J. B. (1974). Corticosterone, prolactin, and growth hormone responses to handling and new environment in the rat. Psychosom. Med. 36, 241-247.

Burn, C. C., Peters, A., Day, M. J., and Mason, G. J. (2006). Long-term effects of cage-cleaning frequency and bedding type on laboratory rat health, welfare, and handleability: a cross-laboratory study. Lab. Anim. 40, 353-370.

Capdevila, S., Giral, M., Ruiz De La Torre, J. L., Russell, R. J., and Kramer, K. (2007). Acclimatization of rats after ground transportation to a new animal facility. Lab. Anim. 41, 255-261.

Crabbe, J. C., Wahlsten, D., and Dudek, B. C. (1999). Genetics of mouse behavior: interactions with laboratory environment. Science 284, 1670-1672.

Diamond, M. C., Ingham, C. A., Johnson, R. E., Bennett, E. L., and Rosenzweig, M. R. (1976). Effects of environment on morphology of rat cerebral cortex and hippocampus. J. Neurobiol. 7, 75-85.

Diamond, M. C., Rosenzweig, M. R., Bennett, E. L., Lindner, B., and Lyon, L. (1972). Effects of environmental enrichment and impoverishment on rat cerebral cortex. J. Neurobiol. 3, 47-64.

Doerning, B. (1999). "Effects of routine animal husbandry, and experimental procedures on physiological parameters of rats," in Workshop on Refinements (in) Toxicology Testing: Hosted by the Humane Society of the United States, New Orleans, LA.

Duke, J. L., Zammit, T. G., and Lawson, D. M. (2001). The effects of routine cage-changing on cardiovascular and behavioral parameters in male Sprague-Dawley rats. Contemp. Top. Lab. Anim. Sci. 40, 17-20.

Elliott, B. M., and Grunberg, N. E. (2005). Effects of social and physical enrichment on open field activity differ in male and female Sprague-Dawley rats. Behav. Brain Res. 165, 187-196.

Flores, C. M., Hernandez, M. C., Hargreaves, K. M., and Bayer, B. M. (1990). Restraint stress-induced elevations in plasma corticosterone and beta-endorphin are not accompanied by alterations in immune function. J. Neuroimmunol. 28, 219-225.

Gornicka-Pawlak, E., Jablonska, A., Chylinski, A., and Domanska-Janik, K. (2009). Housing conditions influence motor functions and exploratory behavior following focal damage of the rat brain. Acta Neurobiol. Exp. (Wars) 69, 62-72. 
Hatch, A., Wiberg, G. S., Balazs, T., and Grice, H.C. (1963). Long-term isolation stress in rats. Science 142, 507.

Johnson, R. N., Desisto, M. J. Jr., and Koenig, A. B. (1972). Social and developmental experience and interspecific aggression in rats. J. Comp. Physiol. Psychol. 79, 237-242.

Kacergis, J. B., Jones, R. B., Reeb, C. K., Turner, W. A., Ohman, J. L., Ardman, M. R., and Paigen, B. (1996). Air quality in an animal facility: particulates, ammonia, and volatile organic compounds. Am. Ind. Hyg. Assoc. J. 57, 634-640.

Kim, J. J., Lee, H. J., Welday, A. C., Song, E., Cho, J., Sharp, P. E., Jung, M.W., and Blair, H. T. (2007). Stress-induced alterations in hippocampal plasticity, place cells, and spatial memory. Proc. Natl. Acad. Sci. U.S.A. 104, 18297-18302.

Morgan, M., and Einon, D. (1975). Incentive motivation and behavioral inhibition in socially-isolated rats. Physiol. Behav. 15, 405-409.

National Institutes of Health. (2010). Guide for the Care and Use of Laboratory Animals, 8th Edn. Washington, DC: The National Academies Press.

Patterson-Kane, E. P., Hunt, M., and Harper, D. (2004). Short communication: rat's demand for group size. J. Appl. Anim. Welf. Sci. 7, 267-272.

Reber, S. O., and Neumann, I. D. (2008). Defensive behavioral strategies and enhanced state anxiety during chronic subordinate colony housing are accompanied by reduced hypothalamic vasopressin, but not oxytocin, expression. Ann. N. Y. Acad. Sci. 1148, 184-195.

Richter, S. H., Garner, J. P., Auer, C., Kunert, J., and Wurbel, H. (2010). Systematic variation improves reproducibility of animal experiments. Nat. Methods 7, 167-168.

Richter, S. H., Garner, J. P., Zipser, B., Lewejohann, L., Sachser, N., Touma, C., Schindler, B., Chourbaji, S., Brandwein, C., Gass, P., Van Stipdonk, N., Van Der Harst, J., Spruijt, B., Voikar, V., Wolfer, D. P., and Wurbel, H. (2011). Effect of population heterogenization on the reproducibility of mouse behavior: a multi-laboratory study. PLoS ONE 6, e16461. doi: 10.1371/journal.pone.0016461
Rosenzweig, M. R., Bennett, E. L., and Diamond, M. C. (1967). Effects of differential environments on brain anatomy and brain chemistry. Proc. Annu. Meet. Am. Psychopathol. Assoc. 56, 45-56.

Rosenzweig, M. R., Krech, D., Bennett, E. L., and Diamond, M. C. (1962). Effects of environmental complexity and training on brain chemistry and anatomy: a replication and extension. J. Comp. Physiol. Psychol. 55, 429-437.

Saibaba, P., Sales, G. D., Stodulski, G., and Hau, J. (1996). Behaviour of rats in their home cages: daytime variations and effects of routine husbandry procedures analysed by time sampling techniques. Lab. Anim. 30, 13-21.

Sapolsky, R. M., Krey, L. C., and Mcewen, B. S. (1984). Glucocorticoid-sensitive hippocampal neurons are involved in terminating the adrenocortical stress response. Proc. Natl. Acad. Sci. U.S.A. 81, 6174-6177.

Schnecko, A., Witte, K., and Lemmer, B. (1998). Effects of routine procedures on cardiovascular parameters of Sprague-Dawley rats in periods of activity and rest. J. Exp. Anim. Sci. 38, 181-190.

Sharp, J., Zammit, T., Azar, T., and Lawson, D. (2003). Stress-like responses to common procedures in individually and group-housed female rats. Contemp. Top. Lab. Anim. Sci. 42, 9-18.

Sharp, J. L., Zammit, T. G., Azar, T. A., and Lawson, D. M. (2002a).Stress-like responses to common procedures in male rats housed alone or with other rats. Contemp. Top. Lab. Anim. Sci. 41, 8-14.

Sharp, J.L.,Zammit, T.G., and Lawson,D.M.(2002b).Stresslike responses to common procedures in rats: effect of the estrous cycle. Contemp. Top. Lab. Anim. Sci.41, 15-22. Singewald, G. M., Nguyen, N. K., Neumann, I. D., Singewald, N., and Reber, S. O. (2009). Effect of chronic psychosocial stress-induced by subordinate colony (CSC) housing on brain neuronal activity patterns in mice. Stress 12, 58-69.

Thulin, H., Bjorkdahl, M., Karlsson, A. S., and Renstrom, A. (2002). Reduction of exposure to laboratory animal allergens in a research laboratory. Ann. Occup Hyg. 46, 61-68.
Tucker, H. A., Petitclerc, D., and Zinn, S. A. (1984). The influence of photoperiod on body weight gain, body composition, nutrient intake and hormone secretion. J. Anim. Sci. 59, 1610-1620.

Van Der Staay, F. J. (2006). Animal models of behavioral dysfunctions: basic concepts and classifications, and an evaluation strategy. Brain Res. Rev. 52, 131-159.

Van Der Staay, F. J., and Steckler, T. (2002). The fallacy of behavioral phenotyping without standardisation. Genes Brain Behav. 1, 9-13.

Van Ruiven, R., Meijer, G. W., Wiersma, A., Baumans, V., Van Zutphen, L. F., and Ritskes-Hoitinga, J. (1998). The influence of transportation stress on selected nutritional parameters to establish the necessary minimum period for adaptation in rat feeding studies. Lab. Anim. 32, 446-456.

Wahlsten, D., Metten, P., Phillips, T. J., Boehm, S. L. II, Burkhart-Kasch, S., Dorow, J., Doerksen, S., Downing, C., Fogarty, J., Rodd-Henricks, K. Hen, R., Mckinnon, C. S., Merrill, C. M., Nolte, C., Schalomon, M., Schlumbohm, J. P., Sibert, J. R., Wenger, C. D., Dudek, B. C., and Crabbe, J. C. (2003). Different data from different labs: lessons from studies of gene-environment interaction. $J$. Neurobiol. 54, 283-311.

Wolfer, D. P., Litvin, O., Morf, S., Nitsch, R. M., Lipp, H. P., and Wurbel, H. (2004). Laboratory animal welfare: cage enrichment and mouse behaviour. Nature 432, 821-822.

Received: 31 March 2011; accepted: 01 July 2011; published online: 27 July 2011

Citation: Prager EM, Bergstrom HC, Grunberg NE and Johnson LR (2011) The importance of reporting housing and husbandry in rat research. Front. Behav. Neurosci. 5:38. doi: 10.3389/fnbeh.2011.00038

Copyright (c) 2011 Prager, Bergstrom, Grunberg and Johnson. This is an open-access article subject to a nonexclusive license between the authors and Frontiers Media SA, which permits use, distribution and reproduction in other forums, provided the original authors and source are credited and other Frontiers conditions are complied with. 